Conclusions An ICU stay can have significant, long-lasting impacts on young people and their families. This is the first panEuropean survey to investigate ICU care for this group. We identified significant variation in adherence to quality standards. Some of this may be culturally influenced but there are also differences in less obviously controversial measures e.g. DVT prophylaxis. Further qualitative work is planned.

\section{Big Data Studies}

\section{0-006 FOLLOW - UP OUTCOMES FROM THE BOOST-II UK TRIAL OF OXYGEN SATURATION TARGETING IN PRETERM INFANTS}

B Stenson, P Brocklehurst, P Cairns, S Deshpande, BW Fleck, HL Halliday, E Juszzzak, A King, N Marlow, W Tin, S Wardle. BOOST II UK Collaborative Group, National Perinatal Epidemiology Unit, Oxford, UK

\subsection{6/archdischild-2014-307384.73}

Background and aims The optimal target range for pulse oximeter saturation $\left(\mathrm{SpO}_{2}\right)$ in extremely preterm infants is unknown. BOOST-II UK is one of 5 international studies that have recently investigated this.

Methods Preterm infants born before 28 weeks' gestation were randomised within $24 \mathrm{~h}$ of birth to an $\mathrm{SpO}_{2}$ target range of 85$89 \%$ or $91-95 \%$. The intervention used masked offset oximeters and was continued until 36 weeks' gestation. The primary outcome was a composite of death or serious neurosensory disability (SND) in survivors at age 2 corrected for prematurity, evaluated in 745 infants cared for using updated trial oximeters. A sensitivity analysis restricted to infants assessed by a Bayley III examination and a secondary analysis including a further 228 infants who were studied before the oximeters were updated were also performed.

Results The primary outcome was determined for 722 (96.9\%) of infants.

\begin{tabular}{|c|c|c|c|c|}
\hline & $\begin{array}{l}\text { Lower } \mathrm{SpO}_{2} \text { target } \\
(85-89 \%)\end{array}$ & $\begin{array}{l}\text { Higher } \mathrm{SpO}_{2} \text { target } \\
(91-95 \%)\end{array}$ & $\begin{array}{l}\text { Adjusted risk ratio } \\
\left(^{*}=95 \% \mathrm{Cl}, \dagger=99 \% \mathrm{Cl}\right)\end{array}$ & $P$ value \\
\hline Death or SND & $187 / 366(51.1 \%)$ & $165 / 356(46.3 \%)$ & $1.11(0.98-1.26)^{*}$ & 0.11 \\
\hline Death & $101 / 371(27.2 \%)$ & 69/369 (18.7\%) & $1.38(1.0-1.9) \dagger$ & 0.01 \\
\hline SND & $86 / 265(32.5 \%)$ & 96/287 (33.4\%) & $1.01(0.76-1.34) \dagger$ & 0.96 \\
\hline
\end{tabular}

The sensitivity analysis showed similar results. In the secondary analysis the mortality difference was $4.9 \%(\mathrm{p}=0.05)$. Severe visual loss did not differ between groups.

Conclusions The higher $\mathrm{SpO}_{2}$ target group had $8.5 \%$ greater survival with no increase in serious neurosensory disability. For infants born before 28 weeks" gestation, $\mathrm{SpO}_{2}$ targets below $90 \%$ are not recommended.

\section{0-007 NEONATAL HYPOGLYCEMIA: INTENSIVE TREATMENT OR EXPECTANT MONITORING?}

${ }^{1}$ AAMW van Kempen, ${ }^{2} \mathrm{PF}$ Eskes, ${ }^{3} \mathrm{JH}$ Kok, ${ }^{4} \mathrm{~N}$ Boluyt. ${ }^{1}$ Neonatology, OLVG Hospital, Amsterdam, Netherlands; ${ }^{2}$ Pediatrics, Meander Medical Center, Amersfoort, Netherlands; ${ }^{3}$ Neonatology, Emma Children's Hospital/AMC, Amsterdam, Netherlands; ${ }^{4}$ NA, National Health Care Institute, Diemen, Netherlands

10.1136/archdischild-2014-307384.74
Background The definition of neonatal hypoglycemia is still subject to discussion, resulting in a wide range of treatment protocols.

Objective To compare two expert-based management strategies at both ends of the current treatment-spectrum of 'moderate' neonatal hypoglycemia (plasma glucose $2.0-2.5 \mathrm{mmol} / \mathrm{l}$ ).

Design/methods Otherwise healthy, 'high-risk' newborns $\geq 35$ weeks and $\geq 2000$ gram with moderate hypoglycemia: premature, small- or large-for-gestational-age or infants of diabetic mothers, were randomised to an intensive treatment strategy (aiming at [glucose] $\geq 2.6 \mathrm{mmol} / \mathrm{l}$ ) or an expectant monitoring strategy (aiming at [glucose] $\geq 2.0 \mathrm{mmol} / \mathrm{l})$. Development was assessed at 18 months (corrected) age, using the Bayley Scales of Infant Development (BSID-III). The study was designed as a non-inferiority trial.

Results In $84 \%$ of the 691 enrolled infants the BSID-III was performed. Cognitive and motor outcomes were comparable in both treatment arms (Table). The results were similar in the overall analysis and in the subgroups.

\begin{tabular}{|c|c|c|c|}
\hline & Intensive Treatment & Expectant Monitoring & Mean Difference $(95 \% \mathrm{Cl})$ \\
\hline BSID-Cognitive & $103.6 \pm 10.9$ & $104.6 \pm 11.4$ & $1.0(-0.8 ;+2.8)$ \\
\hline BSID-Motor & $101.8 \pm 10.6$ & $101.6 \pm 11.7$ & $-0.2(-2.1 ;+1.6)$ \\
\hline
\end{tabular}

The plasma glucose concentration was higher in the intensive treatment group: $+0.24 \mathrm{mmol} / 1(+0.31 ;+0.16)$. Hypoglycemia episodes (after randomization) occurred more frequently in the expectant monitoring group (70\% vs. 57\%, p < 0.001). More infants in the intensive treatment group received additional feeding (94\% vs. $76 \%)$, tube-feeding (12\% vs. $4 \%)$ and/or intravenous glucose $(20 \%$ vs. $6 \%)$ (all: $\mathrm{p}<0.001)$.

Conclusion An expectant monitoring strategy is not inferior to intensive treatment with regard to developmental outcome at 18 months in otherwise healthy newborn infants $\geq 35$ weeks and $\geq 2000$ gram with moderate hypoglycemia.

\section{0-008 EARLY BIFIDOBACTERIUM BREVE BBG-001 TO PREVENT NECROTISING ENTEROCOLITIS, LATE-ONSET SEPSIS AND DEATH: THE PIPS TRIAL}

${ }^{1} \mathrm{KL}$ Costeloe, ${ }^{2} \mathrm{M}$ Wilks, ${ }^{3} \mathrm{P}$ Hardy, ${ }^{3} \mathrm{C}$ Nelis, ${ }^{2} \mathrm{MR}$ Millar. ${ }^{1}$ Paediatrics, Queen Mary University of London, London, UK; ${ }^{2}$ Microbiology, Barts Health NHS Trust, London, UK; ${ }^{3}$ National Perinatal Epidemiology Unit, University of Oxford, Oxford, UK

\subsection{6/archdischild-2014-307384.75}

Background Interpretation of published trials of probiotics in preterm infants is complicated by the use of multiple bacterial strains and exclusion from some trials of babies at high-risk of complications.

Objective To evaluate a single strain of Bifidobacterium breve in an unselected population of preterm infants.

Methods Multi-centre double blind Randomised Placebo Controlled Trial of Bifidobacterium breve BBG-001, 2.1 to $5.3 \times 10^{8}$ cfu daily, ( $B$ breve) in infants below $31 \mathrm{w}$ gestation randomised before $48 \mathrm{~h}$. Primary outcomes were necrotising enterocolitis (NEC) $\geq$ Bell stage 2, late onset sepsis (LOS) and death. Results are presented by intention to treat adjusted for sex, gestation and randomisation within $24 \mathrm{~h}$ and allowing for clustering of multiples. 